\title{
IMAGERY REHEARSAL THERAPY IN NIGHTMARES AFTER A TRAUMATIC EXPERIENCE: A CASE STUDY
}

\author{
EDUARDO FERNÁNDEZ-JIMÉNEZ \\ EMMA VIDAL-BERMEJO \\ DIANA HERNANDO-MANRIQUE \\ ANA HOSPITAL-MORENO \\ Department of Psychiatry, Clinical Psychology and Mental Health, La Paz University Hospital. IdiPAZ. Madrid (Spain)
}

\begin{abstract}
BACKGROUND
- In people with posttraumatic stress disorder, insomnia and trauma-related nightmares are one of the most refractory symptoms (Kobayashi \& Howell, 2018).
\end{abstract}

\section{OBJECTIVE}

eTo present a brief intervention, based in the Imagery Rehearsal Therapy (IRT), in a patient who deliberately refused to sleep in order to avoid trauma-related nightmares.

\section{MATERIALS AND METHODS \\ A 20-year-old woman attended a Mental Health Unit in Colmenar Viejo (Madrid, Spain) for nightmares about sexual abuse suffered in her adolescence. \\ The patient has attended two sessions to date, since February 2019. \\ -During the first session, an anamnesis, psychoeducation about trauma-related responses and coordination with Psychiatry for prescribing hypnotics were carried out. After the first dose of the drug, the patient quit it due to experiencing nightmares, and continued to avoid sleeping with consumption of energy drinks with taurine (approximately 6-7 units per day). \\ -In the next session, a week later, the IRT was introduced. Since the patient had already been using a diary to narrate her traumatic experiences; she was asked to write an alternative ending to her nightmares, and then mentally rehearse it before sleeping.}

\section{RESULTS}

The patient showed sleep improvement, from sleeping less than an hour a day to 7-8 hours approximately in the following days; with an occasional consumption of energy drinks currently.

- She gave up the treatment in the second session because she said to feel much better.

\section{CONCLUSIONS}

- The patient reported a clinically significant improvement from the first session in which the therapy was introduced, achieving a restful sleep, with a decrease in nightmares as well as a mood improvement.

Therefore, the IRT has been both effective and efficient for this patient, as was observed in other studies (Krakow et al., 2001). 